\title{
EuroMAB Meeting 2013, Frontenac Arch Biosphere Reserve, Brockville (Ontario, Canada), 15-19 October 2013 - www.euromab2013.com
}

The main theme for this 4-day conference will be community engagement to achieve MAB objectives of UNESCO's Man and the Biosphere Programme, with the fourth day dedicated to sustainable tourism. This meeting is an excellent networking opportunity for European and North American biosphere reserves, MAB National Committees and scientists as well as a perfect occasion to promote biodiversity conservation and sustainable development around the world. The outcome of the conference will be shared with stakeholders and policy-makers dealing with biodiversity conservation and sustainable development issues.

EuroMAB is the largest and oldest of the Man and the Biosphere (MAB) Regional Networks. EuroMAB is made up of 52 countries, including Canada and the USA, and 284 biosphere reserves. Bringing together almost half of the World Network of Biosphere Reserves, the EuroMAB Network is a platform for sharing knowledge, know-how and experience of sustainable development and a collective tool for supporting sustainable development practices among biosphere reserve coordinators, scientists and MAB National Committees. Since the first meeting in 1986 in České Budêjovice, Czech Republic, the MAB National Committees and biosphere reserve co-ordinators of EuroMAB have met almost every two years. Previous EuroMAB conferences have been held in Minsk, Belarus (1997), Cambridge, UK (2000), Rome, Italy (2002), Hernstein, Austria (2005), Antalya, Turkey (2007), Stará Lesná, Slovakia (2009), and Lundsbrunn, Sweden (2011). EuroMAB meetings are dedicated to bringing together biosphere reserve coordinators, biosphere reserve experts, MAB National Committees and partner institutions.

Read more about the EuroMAB programme on http://www.unesco.org/new/en/natural-sciences/environment/ ecological-sciences/man-and-biosphere-programme/networks/euromab/
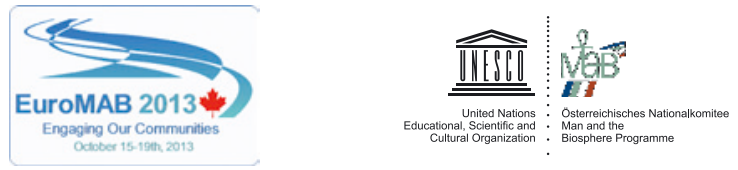

Parks discussed in this issue

Abbreviations: NP - National Park; BR - Biosphere Reserve; p. - page

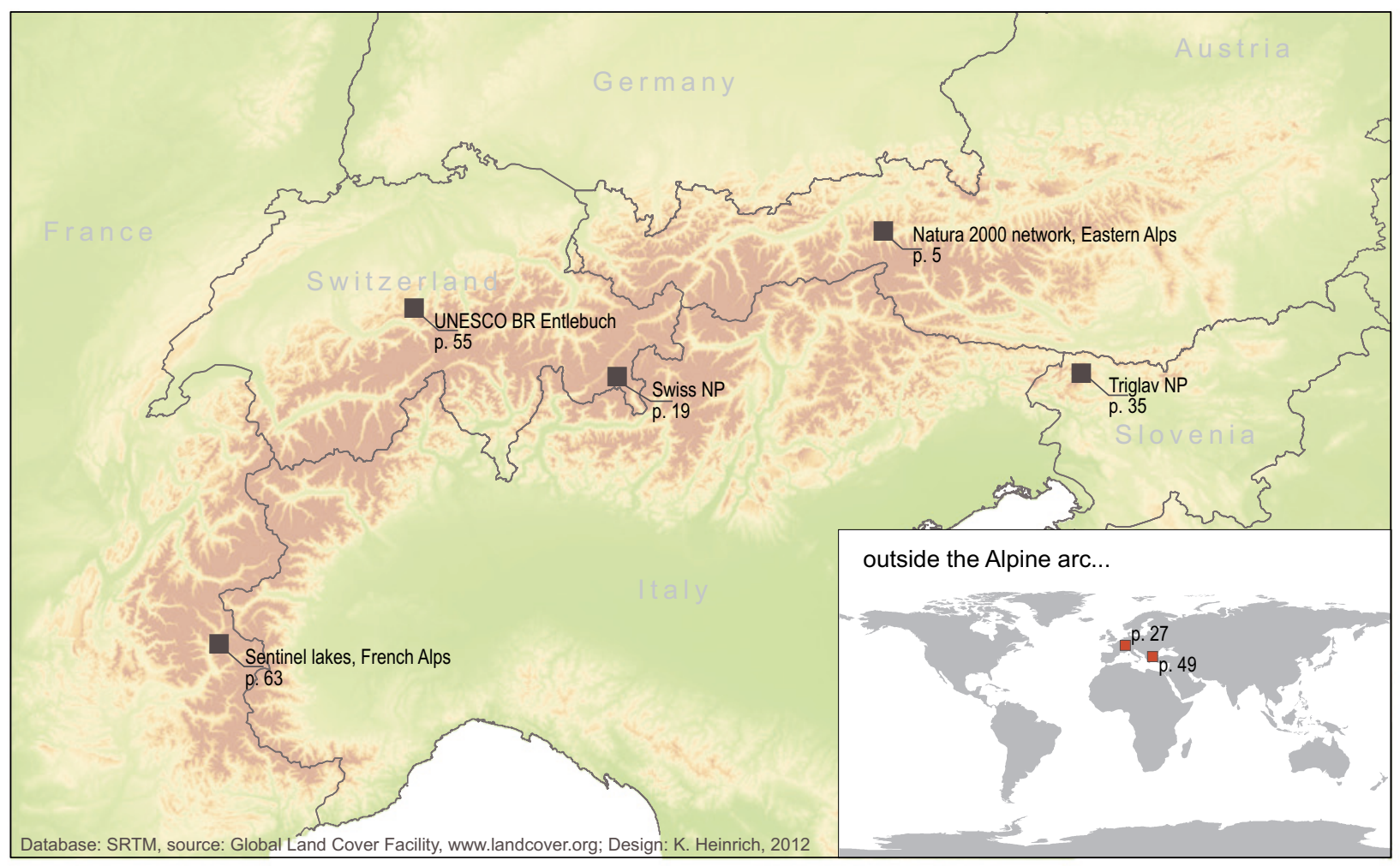

